\title{
PENINGKATAN PARTISIPASI KESADARAN DAN KEWASPADAAN MASYARAKAT TERHADAP ANCAMAN HUMAN SECURITY AKIBAT KEJAHATAN BENCANA ASAP DI DESA SUKA DAMAI KABUPATEN ROKAN HULU
}

Cite as

Alfajri, A., Luerdi, L., \& Utomo, F. (2016). Peningkatan Partisipasi Kesadaran dan Kewaspadaan Masyarakat Terhadap Ancaman Human Security Akibat Kejahatan Bencana Asap di Desa Suka Damai Kabupaten Rokan Hulu. Prosiding Hasil Pengabdian Masyarakat, 1-7. https://doi.org/10.5281/zenodo.5831227

Details:

Authors: (1) Alfajri, (2) Luerdi, and (3) Feriandri Utomo

Publication date: November 29, 2016

DOI: $10.5281 /$ zenodo. 5831227

ISBN: 978-602-61188-0-6

Published in: Prosiding Hasil Pengabdian Masyarakat, Universitas Abdurrab, Pekanbaru, pp. 1-7 (978-602-61188-0-6).

Meeting: Seminar Hasil Pengabdian Kepada Masyarakat, Pekanbaru, 29 November 2016 


\title{
PENINGKATAN PARTISIPASI KESADARAN DAN KEWASPADAAN MASYARAKAT TERHADAP ANCAMAN HUMAN SECURITY AKIBAT KEJAHATAN BENCANA ASAP DI DESA SUKADAMAI, KABUPATEN ROKAN HULU
}

\author{
Alfajri ${ }^{1)}$, Feriandri Utomo $0^{2)}$, Luerdi $^{1)}$, Andree $^{1)}$ \\ 1)Program Studi Ilmu Hubungan Internasional Universitas Abdurrab \\ 2) Program Studi Pendidikan Dokter Universitas Abdurrab \\ Surel: alfajri@univrab.ac.id
}

\begin{abstract}
Haze as a manmade disaster crime in Riau Province (Indonesia in general) is not only detrimental to economic, political, social, cultural, education, health, defence and security sectors, but it also can cause loss of life. Sukadamai village is located in Kecamatan Ujungbatu, Rokan Hulu regency has a same opportunity to be affected by the haze as all other villages in the province of Riau. The village has quite a lot of elementary schools, kindergartens and Early Childhood Development Prograin, which are vulnerable to haze disaster. However, the level of awareness and vigilance against haze disaster in the village is still low. The problem is exacerbated by the lack of socialization about the dangers caused by the haze and methods that can be used to deal with the haze threat. Therefore, efforts are required to increase the awareness and participation of local communities which related to human security threats as the result of haze disaster crime that occur almost annually. This community service tries to increase the awareness and vigilance of the people in the village about the dangers of haze disaster crime.
\end{abstract}

Keywords: Participation, Awareness, Vigilance, Haze

\begin{abstract}
ABSTRAK
Kejahatan bencana asap di Provinsi Riau (Indonesia pada umumnya) tidak hanya merugikan sektor ekomomi, politik, sosial, budaya, pendidikakan, keshatan, dan pertahanan keamanan, namun juga dapat menyebabkan hilangnya nyawa. Desa Sukadamai, Kec.Ujungbatu, Rokan Hulu memiliki peluang terkena tingkat dasar, taman kanak-kan seluruh Desa di Provinsi Riau. Desa ini memiliki cukup banyak sekolah akibat bencana asap. Namun, tingkat kesadidikan Anak Usia Dini (PAUD) yang rentan menjadi korban rendah. Kondisi ini diperburuk dengan kurangnya kewaspadaan terhadap bencana asap di Desa ini masih mewaspadai kejatahan bencana asap. Oleh sebab sosialisasi tentang bahaya asap dan metode untuk partispasi kesadaran an kewaspadan Oleh sebab itu, diperlukan adanya upaya untuk meningkatkan kejahatan bencana asap yang hampir setiasyarakat setempat terkait ancaman human security akibat tujuan peningkatan kesadaran dan kewaspadan terjadi. Melalui pengabdian masyarakat ini, diharapkan bencana asap dapat tercapai dengan baik.
\end{abstract}

Keywords: Partisipasi, Kesadaran, Kewaspadaan, Asap

\section{PENDAHULUAN}

\section{A) Latar Belakang}

Kejahatan bencana asap di Indonesia dan khususnya di Provinsi Riau masih berpotensi untuk terus terjadi dalam beberapa tahun kedepan, meskipun pemerintah Indonesia sudah meratifikasi Agreement on Transboundary Haze Pollution (AATHP) pada tahun 2014. Masalah kejatahatan bencana asap merupakan panjang. Belasan anak yang perlu diselesaikan dengan solusi jangka pendek, menengah dan jangka diperkirakan sebagai tahunggal dunia di Indonesia akibat polusi asap pada tahun 2015 dan tahun tersebut 
int. pratu Walyyudi, seorang perwira TNI meninggal dumia saat melaksanakan tugas pemadaman kebakiran Latau dan hutan di salah satu kabupatert di Provinsi Riau.

Persoalan asap sangat mengancam humen securith, terutatia di Ptovinsi Rias, termasuk Desa Sukadamai. Dalam konsep human sccario, sesuai laporan Human Developmen PBH (1994), terdapat ? (tujuh) ancaman dalam konxep human secerits. Sccara langsung, terdapat 3 katerogi ancaman keamanan dalam konsep homas seceriby terkait kejahatan bencana asap, yaitu:

1) Keananan Keschatas (Wealh Secwrib) bermakna bahwa individu baris terbebas dari ancaman berbagai penyakit dan harus mendapat ahses perawatan keschatan.

2) Keamanan Lingkungan (Bnvirometental Securio) bermakna manusia harus terhindar dari ancaman kelangkaan dan pencemaran tanah, udara, dan air, sehingga menbuat manusia betah untuk tinggal/ Aabitable. Desa Sukadamai, seperti Desa-Desa lainnya di Provinsi Riau, tidak lagi menjadi tempat yang layak huni saat asap menyclimuti daerah tersebut.

3) Keamanan Politik (Political Security) bermakna bahwa manusia mendapatkan keamanan dan perlindungan dari ancaman pelanggaran Hak Asasi Manusia (HAM). Sesungguhnya, kejahatan bencana asap sudah sangat melanggar Hak Azasi Manusia untuk dapat hidup layak, sekerdar menghirup udara segar. Namun, tentu aktivitas bernasfas normal ini tidak dapat dinikmati disaat asap. kembali terjadi. Selain itu, secara politik, baryaining posifton Indonesia jadi melemah di kawasan ASEAN disebabkan kelambanan Indonesia dalam menyelesaikan persoalan internalnya (asap).

Oleb sebab itu, kegiatan pengabdian masyarakat ini dipandang perlu dan diupayakan untuk memberdayakan masyaxakat dalam rangka meningkatkan pengetahuan, partisipasi kesadaran, dan kewaspadaan masyarakat terhadap kejahatan beneana asap.

\section{B) Permasalahan}

Sesuai dengan latar belakang di atas, maka idenfikasi masalah dalam pengabdian ini adalah sebagai berikut :

1. Rendahnya pengetahuan dan kesadaran masyarakat tentang ancaman human security akibat kejahatan bencana asap.

2. Rendahnya partisipisasi kewaspadaan masyarakat terhadap ancaman human securify akibat kejahatan bencana asap.

Berdasarkan identifikasi masalah yang dimaksud, maka rumusan masalah dalam pengabdian masyarakat ini adalah:

1. Faktor-faktor apa saja yang menjadi penyebab rendahnya pengetahuan, kesadaran, dan partisipasi kewaspadaan masyarakat terhadap bahaya ancaman human security akibat bencana asap?

2. Bagaimana meningkatkan partisipasi kewaspadaan masyarakat di Desa Sukadamai terhadap ancaman human security akibat kejahatan bencana asap?

\section{C) Studi Pustaka}

Kegiatan pengabdian terkait kejahatan bencana asap ini menggunakan teori dan konsep relevan dalam memahami dan menyikapi isu ini. Teori dan konsep yang akan dibahas disini telah banyak dipelajari dan dikembangkan oleh para ahli bidang terkait. Teori dan konsep yang dimaksud adalah teori partisipasi
dan konsep human security.

1) Teori dan Konsep Partisipasi

Menurut Budiono (2005), kata partisipasi memiliki makna sebagai peran serta, atau keikutsertaan seseorang dalam suatu kegiatan bersama-sama dengan orang lain untuk mencapai tujuan tertentu.

Definisi partisipasi menurut Soerjono Sockanto (1993) merupakan setiap proses identifikasi atau menjadi peserta, suatu proses komunikasi atau kegiatan bersama dalam suatu situasi sosial tertentu. Dalam konteks ilmu sosial, terdapat berbagai jenis partisipasi, salah satunya adalah partisipasi sosial. Partisipasi sosial didefinisikan sebagai keterlibatan dalam kegiatan sosial demi kepentingan bersama (Nikrmatullah:
1991)

Sedangkan menurut Isbandi (2007) partisipasi secara umum adalah keikutsertaan seseorang dalam proses pengidentifikasian masalah dan potensi yang ada dalam masyarakat, pemilihan dan pengambilan keputusan tentang alternatif solusi untuk menagani masalah, pelaksanaan upaya mengatasi masalah, dan keterlibatan seseorang dalam proses mengevaluasi perubahan yang terjadi.

Selain itu, peneliti lainnya, yaitu Mikkelsen (1999) mengklasifikasi partisipasi kedalam 6 jenis pengertian sebagai berikut :

a) Partisipasi adalah kontribusi sukarela dari masyarakat kepada proyek tanpa ambil serta dalam
keputusan; 
b) Partisipasi adalah pemekaan pihak masyarakat untuk meningkatkan kemauan menerima dan kemauan untuk menanggapi proyek-proyek pembangunan;

c) Partisipasi adalah keterlibatan sukarela oleh masyarakat dalam perubahan yang ditentukannya sendiri,

d) Partisipasi adalah suatu proses yang aktif, yang mengandung arti bahwa orang atau kelompok yang terkait, mengambil inisiatif dan mengunakan kebebasan untuk melakukan hal itu;

e) Partisipasi adalah pemantapan dialog masyarakat setempat dengan para staf yang melakukan persiapan, pelaksanaan, monitoring proyek, agar memperoleh informasi mengenai konteks local, dan dampak-dampak sosial;

f) Partisipasi adalah keterlibatan masyarakat dalam pembagunan diri, kehidupan, dan lingkungan mereka.

Dari berbagai pandangan para pakar diatas, dapat ditarik suatu benang merah bahwa partisipasi mengandung berbagai unsur sebagai berikut:

a) Adanya keikutsertaan atau keterlibatan akftif dalam suatu peristiwa atau kejadian

b) keterlbiatan tersebut bisa tumbub akibat adanya atau tinggi nya tingkat kesadaran

c) Partisipasi dalam jenis atau kategori apapun bisa sejalan dengan prinsip dasar manajemen yaitu dapat dimualai dari perencanaan, pelaksanaan, monitoring, hingga berakhir sampai tahap evaluasí.

\section{Tujuan Partisipasi}

Adapun tujuan partisipasi menurut Schiller dan Antlov (dalam Hetifah, 2003) sebagai berikut: a). menciptakan visi bersama, b). membangun rencana, c). mengumpulkan gagasan. d). memberi ruang bagi terkumpulnya berbagai gagasan bernas untuk menyelesaikan persoalan-persoalan yang dihadapi oleh masyarakat, e). menentukan prioritas / membuat Pilihan. f).menjaring aspirasi / masukan, g). mengumpulkan informasi / analisis situasi

\section{3) Konsep Human Security}

Menurut diplomat Rob McRae dalam Richard W Mansbach dan Kirsten L Rafferty (2008), human security merupakan konsep keamanan yang menempatkan individu sebagai perhatian utama, dimana manusia memandang hidup dalam kehidupan secara komprehensif meliputi aspek politik, ekonomi, dan lingkungan sosial. Pada tingkatan paling dasar, human security dapat bermakna bebas dari rasa takut.

Konsep human security merupakan bagian dari konsep keamanan non-tradisional yang diusung oleh kalangan pemikir liberalisme dalam studi Hubungan Internasional yang meyakini bahwa aktor dalam. hubungan internasional ataupun politik global tidak selalu negara, namun juga terdapat aktor-aktor lain, diantaranya organisasi internasional, lembaga Non-Governmental Organization (LSM), perusahaan multinasional (multinational corporation) bahkan individu. Dengan demikian isu-isu yang diusung dalam konsep human security juga sangat bervariasi

Untuk pertama kalinya, konsep human security diperkenalkan oleh United Nations Development Program (UNDP) dalam Human Development Report (1994) merupakan badan Perserikatan BangsaBangsa (PBB). Badan ini berpandangan bahwa kejadian-kejadian konflik saat ini lebih banyak terjadi di dalam negara dibandingkan dengan konflik antarnegara. Tentunya, hal ini berbeda dengan masa Perang Dunia I, Perang Dunia II, dan perang dinging yang memang didominasi oleh konflik antarnegara, sehingga isu dan fokus perhatian masih terpusat pada keamanan nasional (national security). Barry Buzan (2000) bahwa:

"keamanan manusia merupakan satu konsep yang problematis, khususnya dijadikan sebagai bagian dari analisis atas keamanan internasional. Bentuk keamanan ini memiliki agenda yang pemahaman keamanan militer-politik tradisionan internasional dapat ditemukan dalam negara senantiasa berkaitan dengan kelangsungan Dalam konteks ini, keamanan bagi suatu

kanci dari pemahaman keamanan bagi suatu bangsa".

mendapat perhatian akibat dominasi isu pencuat sebelum Perang Dunia II, namun kemudian tidak begitu demikian, konsep human security ini kembali antarnegara yang memang marak terjadi saat itu. Meski awal 1990-an. Situasi ini sejalan dengan keinginan PBB momentum pasca berakhirnya Perang Dingin pada PBB turut berperan lebih aktif dalam menginan PBB atas desakan berbagai negara dunia ketiga supaya Isu-isu yang menarik perhatian paikapi berbagai perkembangan isu-isu global kontemporer.

hanya fokus tentang politik internasional, akademisi dan pengambil kebijakan mulai bergerser dan tidak studi hubungan internasional. Isu-isu mang dan keamanan negara dalam pandangan kaum realis dalam kemiskinan, HAM, terrorisme, dII. 
PBB menegaskan upaya nya untuk berpattisipasi secara aktif dalam menyikapi konsep dan isis terkait human security pasca Perang Dingin. Hal ini dibuktikan dengan adanya lapotan Pembaharuan PmB, "Renewing The United Nations" (1997) yang menyatakan bahwa PBB akan memptiotilaskan bidang bidang berikut, yaitu:a) perdamaian, keamanan, dan pelucutan senjata; b) Masalah-masalah ekonomi dain social; c) kerjasama pembangunan; d) lingkungan, habitat dan pembangunan betkelanjutan, e) masalah masalah kemanusiaan, dan; f) penegakan HAM;g) Masyarakat Sipil.

Menurut laporań Human Developlement PBB (1994), terdapat tujuh kategori ancanan dalam konsep Human Security yaitu :

- Keamanan Ekonomi (Economic Security) bermakna bahwa tiap individu harus aman dari ancaman pemenuhan kebutuhan dasar (basic income).

- Keamanan Pangan (Food Security) bermakna bahwa tiap individu harus bebas dari ancaman ketersediaan makanan.

- Keamanan Kesehatan (Health Security) bermakna bahwa individu harus terbebas dari aneaman berbagai penyakit dan harus mendapat akses perawatan kesehatan.

- Keamanan Lingkungan (Environmental Security) bermakna manusia harus terhindar dari ancaman kelangkaan dan pencemaran tanah, udara, dan air, sehingga membuat manusia betah unituk tinggal/ habitable.

- Keamanan Pribadi (Personal Security) mengacu pada kebebasan individu dari kejahatan dan kekerasan, khususnya perempuan dan anak-anak.

- Keamanan Komunitas (Community Security) bermakna bahwa manususia harus aman dalam hal martabat budaya dan perdamaian antar-komunitas indigenous nya

- Keamanan Politik (Political Security) bermakna bahwa manusia mendapatkan keamanan dan perlindungan dari ancaman pelanggaran Hak Asasi Manusia (HAM).

\section{D) Tujuan Pengabdian}

Tujuan kegiatan pengabdian ini adalah sebagai berikut:

1) Untuk memberikan penguatan terhadap pengetahuan, kesadaran dan pertisipasi kewaspadaan maysarakat terhadap bahaya kejahatan bencana asap.

2) Untuk menginformasikan tentang bahaya kejahatan bencana asap dan metode-metode (langkah-langkah teknis) yang dapat dilakukan untuk mengurangi dampak permasalahan asap selama ini.

3) Untuk meningkatkan peran partisipasi masyarakat dalam mewaspadai kejahatan bencana asap.

\section{BAHAN DAN METODE}

Pengabdian ini dilaksanakan pada tanggal 16-17 Desember 2016 di Aula Kantor Desa Sukadamai, Kecamatan Ujungbatu Rokan Hulu. Bahan dan atau alat peraga utama yang dipakai adalah masker N-95, sebagai masker yang tepat untuk digunakan saat kabut asap pekat. Dari hasil diskusi di lapangan, ditemukan bahwa masyarakat di Desa Sukadamai Ujungbatu (terutama pihak PAUD, TK dan SD, termasuk perangkat Desa) tidak memahami tentang level pencemaran udara, misal PM 200-300, tidak mengetahui sumber untuk mendapatkan informasi tingkat pencemaran udara (seperti website Kementrian L.H). Pada saat yang sama, Desa ini juga tidak memiliki alat pengukur tingkat pencemaran udara (ISPU). Olch sebab itu, metode yang diterapkan berupa presentasi dan tanya jawab dengan peserta yang hadir. Selain itu para dosen kegiatan pengabdian ini juga memberikan penyampaian informasi dan langkah-langkah teknis untuk meningkatkan partisipasi kesadaran dan kewaspadaan masyarakat terhadap bahaya kejahatan bencana asap.

\section{HASIL DAN PEMBAHASAN}

Kegiatan pengabdian ini menggugah kesadaran masyarakat dan perangkat Desa Sukadamai, Kecamatan Ujungbatu, Rokan Hulu akan penting nya pengetahuan tentang bahaya kejahatan bencana asap. Sebelumnya, mereka tidak mengetahui bagaimana cara mendapatkan informasi tentang tingkat pencemaran udara, karena belum tersedianya papan informasi indeks pencemaran udara (ISPU). Oleh sebab itu, dosen yang melakukan kegiatan pengabdian memberikan informasi dan cara mendeteksi tingkat pencemaran udara website Kementrian Luar Negeri. Selain itu, informasi awal juga dapat diperoleh melalui media sosial (facebook, twitter, dll).

Secara ekonomi, kami juga memaparkan perkiraan total kerugian akibat kabut asap tahun 2015, yaitu mencapai 221 Triliun Rupiah. Selain kerugian bidang lainnya (politik, pertahanan, pendidikan, sosial dan budaya), kejahatan bencana Asap 2015 dan 2016 juga telah merenggut nyawa. Meskipun masyarakat dan perangkat Desa pernah mendengar hal tersebut, namun mereka belum mengetahui jumlah angka korban 
akibat kabut asap. Setelah mengetahui bahwa ada 19 korban nyawa pada tahun 2015 dan I nyawa tahom 2016, mereka cukup kaget dengan angka tersebut dan mulai menunjukkan ekspresi keseriusan.

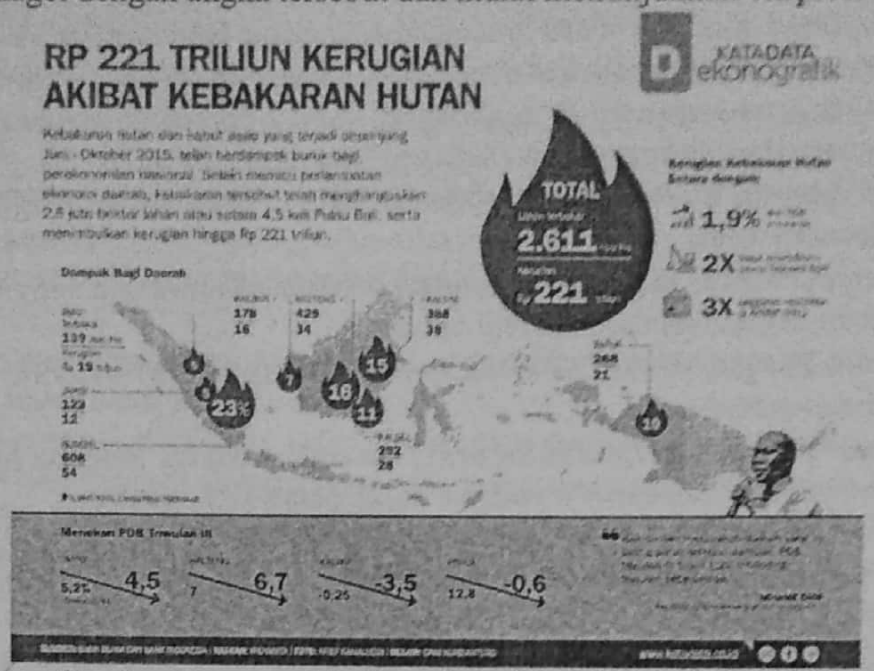

Gambar Presentasi 1: Kerugian diprediksi senilai $221 \mathrm{~T}$

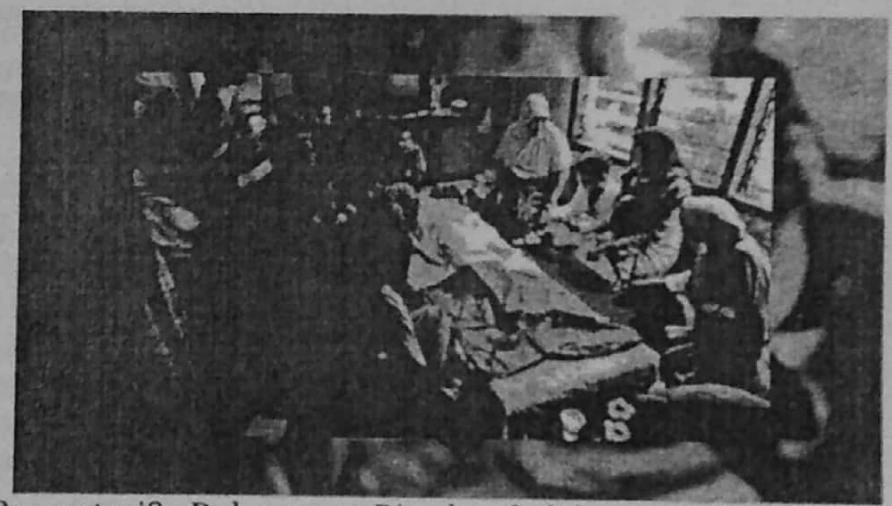

Gambar Presentasi2 : Duka warga Riau kembali bertambah karena kabut asap.

(MSyukur/Liputan6.com)

Ramadhani Lutfi Aeril, pelajar berusia 9 tahun

Secara teknis, kami juga menyampaikan bahwa anak-anak dibawah umur sebaiknya tetap berada didalam rumah dan tidak masuk ke sekolah pada saat ISPU mencapai angka PM200-300 (Sangat Tidak Sehat). Kami juga merekomendasikan kepada seluruh perwakilan PAUD, TK, SD dan perangkat Desa yang hadir agar merekomendasikann kepada Dinas Pendidikan dan atau Bupati untuk meliburkan Sekolah saat indeks pencemaran udara sudah sampai pada tingkat sangat tidak sehat (partikulat2 asap/pm200-300). Khusus PAUD dan TK yang berada dibawah kendali Desa, kami sarankan agar kepala Desa mengambil kebijakan untuk meliburkan sekolah tanpa menunggu informasi dari Dinas. Malaysia dan Singapura juga meliburkan sekolah pada tingkat pencemaran udara yang sama (sangat tidak sehat)

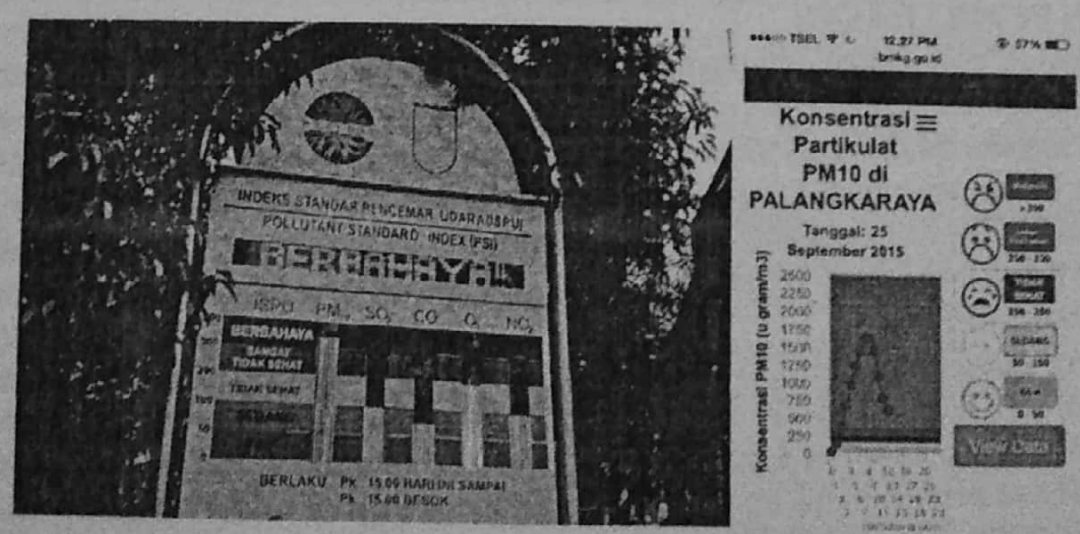

Gambar Presentasi 3: ISPU dan PM10 
Masker yang diganakan anat kabut asap bukandah maskef bedah, karena hal tersebat tidak akan membantu. Standar internasional yang dipaka untuk kabot asap adalah masker N95. Hal ini kami tekankan, kama saat kabut asap terjadi, dinas kesehatan pun membagikan masker bedah, bukan masker N95.
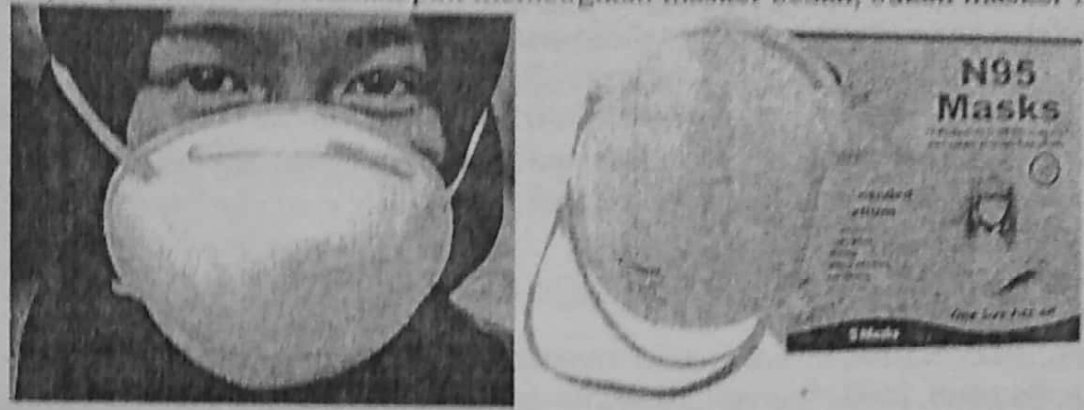

Gambar Presentasi 4: Masker N95

Pada akhir pemaparan dan diskusi kami selama dua hari, pihak Desa dan seluruh yang hadir mengueapkan terima kasih sebesar-besarnya kepada para dosen pengabdian, dan tentu nya kepada Universitas Abdurab, Kegiatan pengabdian ini berhasil mengungkap bahwa sebab rendah tingkat partisipasi kesaradaran dan kewaspadaan terhadap bahaya kejatahan asap disebabkan oleh setidaknya tiga hal: pertama, rendahnya pengetahuan terkait isu dimaksud; kedua: kurangnya sosialisasi dari berbagai pihak (pemerintah, dunia akademisi, dII); ketiga: minimnya ketersediaan informasi dan alat pendukung informasi terkait (seperti papan ISPU), Kami juga mengueapkan terima kasih atas kerjasama yang ditunjukkan oleh pihak Desa Sukadamai dan seluruh komponen yang hadir. Kemudia, kami juga sampaikan bahwa sebagai tindak lanjut hubungan baik ini, kami bersedia untuk dijadikan narasumber, atau tempat berkonsultasi terkait dengan permasalahan dan dampak kabut asap ini (baik dari aspek kesehatan, maupun aspek-aspek terkait lainnya.

Foto-Foto Kegiatan:
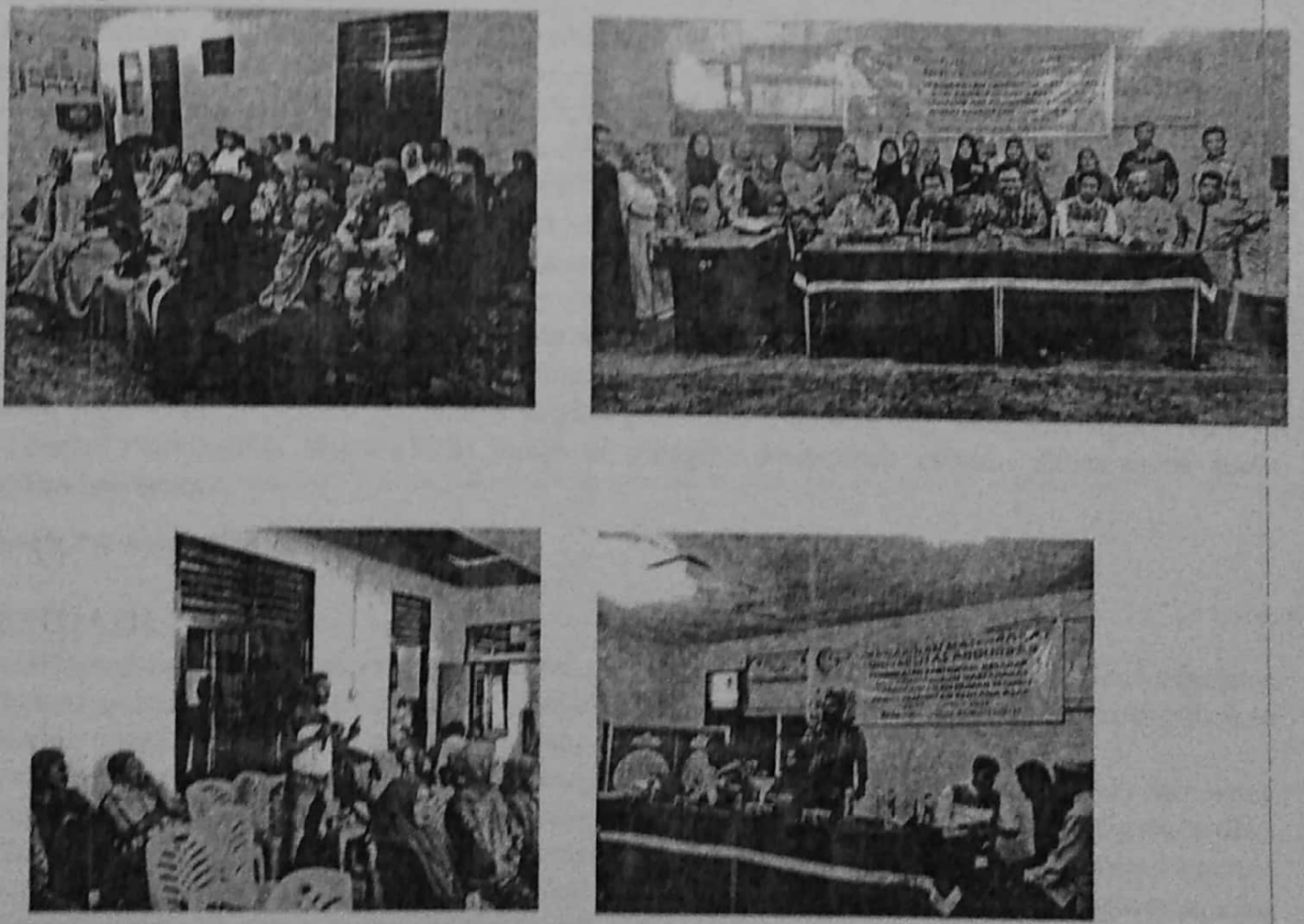

\section{KESIMPULAN}

Acara pengabdian masyarakat ini díkuti dengan antusias oleh seluruh pihak yang hadir. Mereka antusias bertanya dan mulai menyadari bahwa kejahatan beneana asap adalah persoalan serius bukan persoalan 


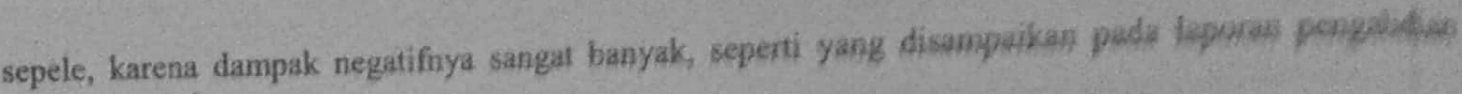
masyarakat ini.

\section{UCAPAN TERIMAKASII}

Kami mengucapkan terima kasih kepada pihak Universitas Abdumah dan Yayasail yang mecnaung wy: yang telah memberikan hibah bagi pelaksanaan kegiatan ini. Kami juga mengucaphon kerma kesidy kequia. Kepala Desa Sukadamai, Kec. Ujungbatu, Bapak. Muhammad Ramtani Rokan, M Pd, beschlt jajwant perangkat Desa dan seluruh perwakilan PAUD, TK, SD dan mayarakat selingkungan Desa Silkadanam yase turut terlibat dalam kegiatan pengabdian masayarakat ini. Semoga kedepan tetep terjoling fuburgan fiak kerjasama yang baik antara kedua belah pihak.

\section{DAFTAR PUSTAKA}

\section{Buku:}

Budiono. 2005. Kamus Ilmiah populer internasional. Alumni Surahaya, 2005

Hetifah, Sumarto. 2003. "Inovasi, Partisipas dan Good Governance Jakarta: Yayasan Ghor indowecia Isbandi, Rukminto Adi. 2007. Perencanaan Paritisipatoris Berbasis Aset Komusnitas: Dari Pemsikiren Menuju Penerapan Depok: Fisíp UI Press

Mikkelsen, Britha. 1999. Metode Penelitian Partisipatoris dan Upaya-Upaya Peaberideyaan sethuld bwhy pegangan bagi para praktisi lapangan. Jakarta Yayasan Obor.

Nikmatullah, Dewangga.1991. Partisipasi Pemimpin Desa dalam Pembinaan Kelompok Tai \&i Rawn Srigi, Lampungan Selatan: Badan Penelitian Universitas Gadjah Mada.

Soekanto, Soerjono. 2004. Pembangunan Masyarakat Berwawasan Partisipasi. Yayasan Obor ludonesie Jakarta

Richard W. Mansbach and Kirsten L. Rafferty, 2008. Introduction to Global Politirs, Routledge, Asew York.

\section{Artikel dalam jurnal atau makalah:}

Buzan, Barry, 2000. "Human Security: What It Means, and What ft Entails", Makalah yang dipresentasikan pada the $14^{\text {th }}$ Asia Pacific Roundiable on Confidence Building and Conflies Resolution, Kuala Lumpur, hal. 1-3.

\section{Internet:}

"Human Development Report". 1994. diakses online: http:/hdr.undporg/sites/defaulufiles/reponts/255/hdr 1994 en complete nostats odf

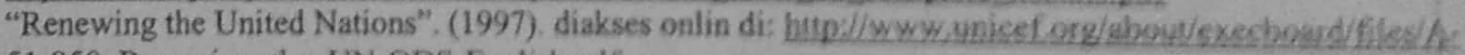
51-950 Renewing the UN-ODS-English. pdf 